\title{
In the line of fire
}

\author{
The bushfires burning in Australia have led to widespread local and global calls for increased efforts to mitigate \\ climate change.
}

N ews coverage of the fires sweeping over Australia, as well as images of the devastating consequences for human wellbeing, infrastructure and wildlife, has led to an outpouring of international sympathy and assistance. In hand with this solidarity comes criticism of Australia's climate policies and an urgent message to world leaders. The unusual extent of the fires has led many to name Australia 'ground zero' for climate change, motivating domestic and international demands for Australia and other wealthy nations to strengthen their mitigation efforts.

In this issue, we feature Comments and Correspondence related to the Australian fires and their relationship to climate change - both in terms of the underlying causes, and in terms of adaptation and mitigation. Although efforts are still under way to establish a link between climate change and these fires ${ }^{1}$, they are unprecedented in terms of the area burned, which an analysis by Matthias Boer and colleagues (see their Correspondence) indicates greatly exceeds previous fires both within Australia and globally. As King et al. write in a related Comment, this is likely to be due to the very dry conditions that Australia has experienced over the past 2 years, brought about by the absence of a La Niña or negative Indian Ocean Dipole event.

The fires come conspicuously in the wake of a year that saw increasing public engagement with climate science and policy, as well as heightened media coverage, as we noted in our first editorial of $2020^{2}$. Events like the Australian bushfires are viewed as a harbinger of a future that is quickly becoming present, although capturing such fires is still a challenge for climate models, as Sanderson and Fisher address in their Comment. The heightened incidence and awareness of such extreme events has seemingly shifted the dialogue around climate change in industrialized countries.

This shift, particularly if it translates into the necessary political action, is welcome but overdue. The science around climate change has been well accepted by researchers for decades, and many countries in the global South have been dealing with the consequences of climate change during this time. For example, changing weather patterns have led to both severe flooding and desertification in Africa, affecting crop

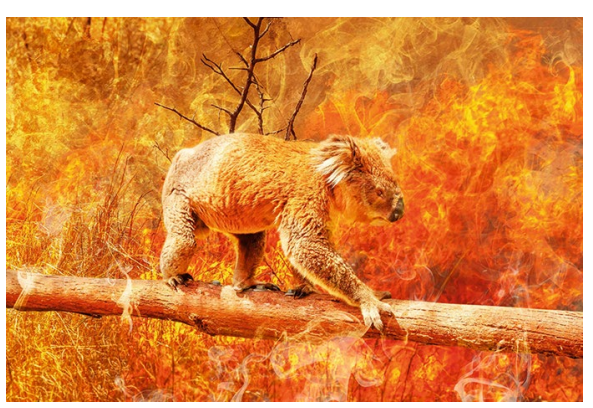

Credit: Benny Marty / Alamy Stock Photo

yields and food security; and low-lying Pacific island states such as Kiribati have been calling for climate mitigation for years as they lose land to rising sea levels.

These impacts, often felt by the most vulnerable members of society and occurring primarily in countries with fewer resources than Australia to cope with them, did little to motivate widespread appeals for emissions reductions in developed countries. Even the effects of climate change felt already in Australia - most notably coral bleaching and reef loss - have done little to change political discourse. What is different about these fires, and why have they been so effective in inspiring calls to action?

One key difference is that Australia plays a much larger role in generating greenhouse gas emissions than, for example, sub-Saharan Africa (15.4 versus 0.8 metric tonnes per capita ${ }^{3}$ ). Australia's role as an industrialized country removes the disconnect between the countries bearing responsibility for climate change, and those bearing the burden. Australia has the potential to mitigate the source of the very problems it is currently fighting.

A second aspect is the direct impact on people and everyday life. The majority of Australians have been affected by the fires ${ }^{4,5}$, whereas coral reef loss is not directly seen by most. This widespread impact challenges the "double reality" in wealthy countries, where the science of climate change is accepted, but the impacts are held at a distance, writes Lesley Head in a Comment that warns against acclimating to such events as the new normal.

The wide availability and accessibility of photos, videos and social media messages from Australia showing the disaster in real time may also play a role. There were few videos of wildlife harmed in the
Amazon fires; yet images of Australia's iconic kangaroos and koalas in front of the flames have inspired many to help by knitting blankets and clothing for the rescued animals. These crafting efforts show engagement with the issues and public concern, write Jager and Coutant in a Correspondence, but also illustrate a disconnect between actions aimed at saving individual animals, and the broader adaptation and political steps needed to preserve species and address the emissions at the source of the problem.

Finally, there is awareness in Australia regarding the context in which the fires and other changes are occurring. Scientists have the long-term records needed to start attributing drought and fires to climate change, and the public have the education and access to information needed to understand the larger implications of the changes that they experience. Nevertheless, Rickards and Watson point out in their Comment that the fires have demonstrated that the very educational and research infrastructure needed to study climate change and its impacts are threatened by climate change itself.

The current engagement brings hope for political change; however, it is also important to remember that, although the effects of climate change are still new or future problems for much of the developed world, they have been felt clearly for years already in other countries. Australia is certainly deserving of compassion and support in the face of the fires. At the same time, it is worthwhile to pause and acknowledge the other places at the frontlines of climate change and to include their stories in the collective motivation for climate action.

Published online: 24 February 2020 https://doi.org/10.1038/s41558-020-0720-5

References

1. Phillips, N. \& Nogrady, B. Nature 577, 610-612 (2020).

2. Editorial. Nat. Clim. Change 10, https://doi.org/10.1038/s41558019-0680-9 (2020)

3. World Bank. Climate Change Indicators. Data available at https://data.worldbank.org/indicator/EN.ATM.CO2E.PC (accessed 5 February 2020).

4. The Australia Institute. Polling-Bushfire crisis and concern about climate change (January 2020); https://go.nature. $\mathrm{com} / 3 \mathrm{aPTLsc}$

5. Martin, S. The Guardian (22 January 2020); https://go.nature. com/3bliqk3 